\title{
Depressive symptoms are doubled in older British South Asian and Black Caribbean people compared with Europeans: associations with excess co-morbidity and socioeconomic disadvantage
}

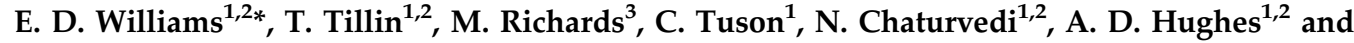 \\ R. Stewart ${ }^{4}$ \\ ${ }^{1}$ International Centre for Circulatory Health, Imperial College London, UK \\ ${ }^{2}$ Institute of Cardiovascular Science, University College London, UK \\ ${ }^{3}$ MRC Unit for Lifelong Health and Ageing, University College London, UK \\ ${ }^{4}$ King's College London (Institute of Psychiatry), London, UK
}

Background. Despite elevated risk profiles for depression among South Asian and Black Caribbean people in the UK, prevalences of late-life depressive symptoms across the UK's three major ethnic groups have not been well characterized.

\begin{abstract}
Method. Data were collected at baseline and 20-year follow-up from 632 European, 476 South Asian and 181 Black Caribbean men and women (aged 58-88 years), of a community-based cohort study from north-west London. The 10item Geriatric Depression Scale was interviewer-administered during a clinic visit (depressive symptoms defined as a score of $\geqslant 4$ out of 10 ), with clinical data (adiposity, diabetes, cardiovascular disease, cognitive function) also collected. Sociodemographic, psychosocial, behavioural, disability, and medical history information was obtained by questionnaire.

Results. Prevalence of depressive symptoms varied by ethnic group, affecting 9.7\% of White European, $15.5 \%$ of South Asian, and $17.7 \%$ of Black Caribbean participants. Compared with White Europeans, South Asian and Black Caribbean participants were significantly more likely to have depressive symptoms (odds ratio $1.79,95 \%$ confidence interval 1.24-2.58 and 1.80, 1.11-2.92, respectively). Adjustment for co-morbidities had most effect on the excess South Asian odds, and adjustment for socioeconomic position had most effect on the elevated Black Caribbean odds.

Conclusions. Higher prevalence of depressive symptoms observed among South Asian people were attenuated after adjustment for physical health, whereas the Black Caribbean increased prevalence was most explained by socioeconomic disadvantage. It is important to understand the reasons for these ethnic differences to identify opportunities for interventions to address inequalities.
\end{abstract}

Received 1 July 2014; Revised 19 November 2014; Accepted 19 November 2014; First published online 13 February 2015

Key words: Depression, ethnic group differences, explanatory factors, prevalence.

\section{Introduction}

Depression is one of the leading causes of morbidity, healthcare use and loss of productivity worldwide (WHO, 2008). Its greater prevalence in older age is thought to be associated in part with chronic disease co-morbidity (Blazer et al. 1991), including cognitive dysfunction (Osborn et al. 2003), and in part with somatic symptoms and related mental disorders, such as anxiety (Yesavage et al. 1982).

\footnotetext{
* Address for correspondence: Dr E. D. Williams, Institute of Cardiovascular Science, University College London, Gower Street, London WC1E 6BT, UK.

(Email: emily.williams@ucl.ac.uk)
}

People of South Asian and Black Caribbean origin form the largest and longest established ethnic minority populations in the UK. Most first-generation migration occurred in the 1950s and 60s, such that the majority are now of pensionable age. Variations in chronic disease prevalence have been identified (Smith et al. 2000), with both South Asian and Black Caribbean groups tending to have worse profiles (Fischbacher et al. 2007; Tillin et al. 2013). Despite marked ethnic group differences in risk factors for depression, including socioeconomic adversity, experience of discrimination, health behaviours, disability and chronic disease (Nazroo, 2003; Karlsen et al. 2005; Craig et al. 2006; Williams et al. 2011, 2012; Tillin et al. 2013), surprisingly few UK studies have characterized ethnic group variations in depression. 
Instead, the limited work has shown mixed results and comprised samples with wide or mid-life age ranges. Some studies have focused on elevated depression in South Asian women (Gask et al. 2011), and discordance with medication use (Hussain \& Cochrane, 2002), yet in older samples, both elevated and equivalent rates of depression among South Asian people compared with Europeans have been reported (Silveira \& Ebrahim, 1995; Lindesay et al. 1997). The sole comparative study of an older UK Black Caribbean sample reported no difference compared with the White population (Silveira \& Ebrahim, 1995). Investigation of explanations for ethnic differences observed has been limited. Studies in the USA comparing the long established African American migrant population with US whites indicate excess or equivalent rates of depression (Husaini \& Moore, 1990; Blazer et al. 1994; Simpson et al. 2007; Williams et al. 2007). Extrapolation to the UK context, however, may be unhelpful as UK Black Caribbeans are first-generation migrants, have different demographic and social characteristics, and are exposed to a different healthcare system; this argument would also apply to migrant populations to other settings outside the UK.

The aim of this paper was to compare depressive symptom prevalences between White European, South Asian and Black Caribbean older people from a community-based sample in West London, and to determine factors that might account for any observed differences, taking advantage of a longitudinal study with exposure measures obtained in both mid and later life. The primary hypothesis was that depressive symptoms would be more common in South Asian and Black Caribbean participants than Europeans. We hypothesized that excess chronic disease and socioeconomic disadvantage might explain elevated depressive symptoms in both ethnic minority groups compared with White Europeans. We also sought to investigate the extent to which exposure to other recognized risk factors for depression might potentially account for any prevalence differences observed. A secondary objective was to evaluate the extent to which the 10-item Geriatric Depression Scale (GDS; D'Ath et al. 1994) used in this study differed in performance between the three ethnic groups.

\section{Method}

We analysed follow-up data from the Southall and Brent REvisited (SABRE) study, a community-based tri-ethnic cohort study of White European, South Asian and African and Black Caribbean individuals living in north-west London between 1988 and 1991 (Tillin et al. 2012) (see Fig. 1). Participants aged 40-69 ( $n=4857 ; 2346$ White, 1710 South Asian, 801 African and Black Caribbean) were randomly selected from age- and gender-stratified general practitioner lists and workplaces at baseline (1988-1991), and were followed up between 2008 and 2011. All South Asian, African and Black Caribbean participants were first-generation migrants. Since just 60 of the African and Black Caribbean participants originated from Africa, we have only included those of Black Caribbean origin in these analyses. Therefore, of the sample included here, all of the Black Caribbean people were born in the Caribbean, while the large majority (79\%) of South Asian participants were born in the Indian subcontinent (69\% India, 8\% Pakistan, 2\% Sri Lanka), with $15 \%$ born in East Africa; approximately half $(53 \%)$ were of Punjabi Sikh origin. Of the White European sample included here, $87 \%$ were born in the UK and $15 \%$ were Irish-born. Ethnicity was interviewer-recorded based on parental origin and appearance and subsequently confirmed by participants. This method of self-assigned ethnicity is in keeping with the UK census categorization (http://www.ons. gov.uk/ons/guide-method/measuring-equality/equality/ ethnic-nat-identity-religion/ethnic-group/index.html\#1), modified to reflect the fact that our participants were all first-generation migrants, with no individuals of mixed ethnicity.

A 20-year follow-up investigation was conducted of all surviving participants (aged 58-88 years). Of the original sample, $93 \%$ were traced, of whom 3433 participants were alive at follow-up, with follow-up data available for 2161 participants (1042 European, 794 South Asian, and 325 Black Caribbean, equating to response rates of $65 \%, 62 \%$ and $59 \%$, respectively). Detailed data on depressive symptoms and explanatory variables were collected from these participants who additionally attended clinic. Only participants with complete data on variables of interest were included in the main analyses $[n=1289$ : White European $n=632$ (27\%), South Asian $n=476$ (28\%), Black Caribbean $n=181(25 \%)]$. All participants gave written informed consent. Approval for the study at baseline was obtained from Ealing, Hounslow and Spelthorne, and University College London research ethics committees, and at follow-up from St Mary's Hospital Research Ethics Committee (ref.07/H0712/109).

\section{Assessments at baseline and follow-up}

Table 1 displays the data collected at baseline and follow-up. Depressive symptoms were ascertained at follow-up only using the 10-item GDS (D'Ath et al. 1994), a widely used screening instrument administered by interviewer. The GDS has been specifically evaluated in previous research within UK ethnic groups (Abas et al. 1998) and a $4 / 10$ cut-off was found to provide best performance against a diagnostic 


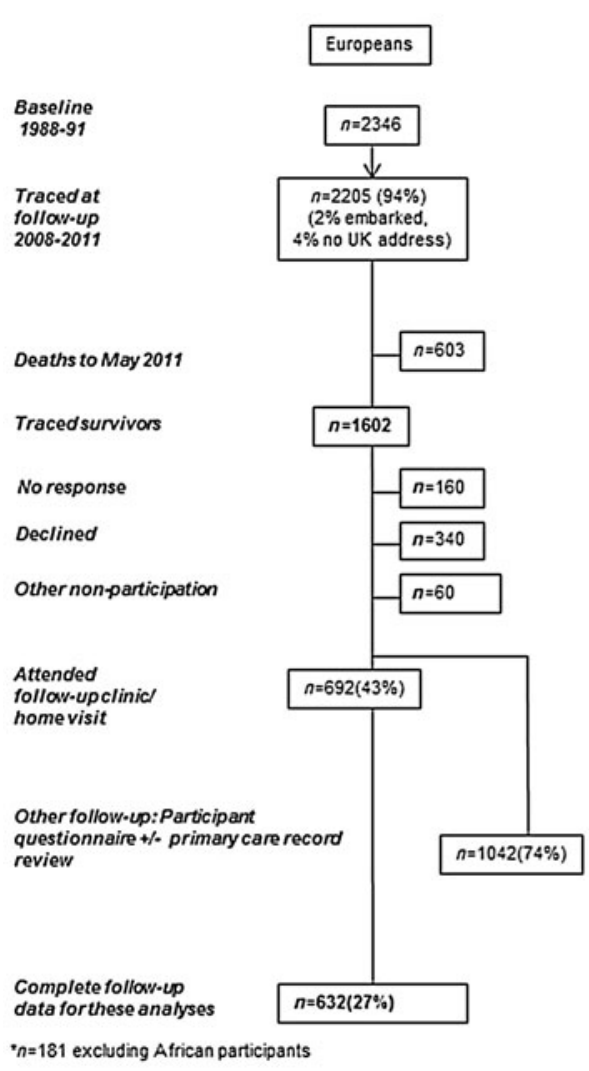

Fig. 1. SABRE study flow diagram.

assessment (Stewart et al. 2001). Within the samples analysed here, the internal consistency for this scale was satisfactory (Cronbach's $\alpha$ : White European $=$ 0.66; South Asian $=0.72$; Black Caribbean $=0.69$ ). At baseline, standard cardiometabolic assessments were performed (following an overnight fast), described elsewhere in detail (Table 1 and Tillin et al. 2012). A self-administered questionnaire included sociodemographic, behavioural and medical history items.

Participants were invited to complete a questionnaire and attend clinic at follow-up (Tillin et al. 2012). Questionnaire data were available for $60 \%$ of traced survivors from the original sample; however, since GDS data were collected during full-day clinic sessions only (conducted by trained research staff/nurses), response rates for this aspect of the study were lower (44\% for White and Black Caribbean, 43\% for South Asian participants).

\section{Statistical analysis}

Age- and sex-adjusted group comparisons (reference category: White Europeans) were performed using analyses of covariance, logistic regression and MannWhitney $U$ tests for continuous, categorical, and nonparametric (unadjusted) variables, respectively.
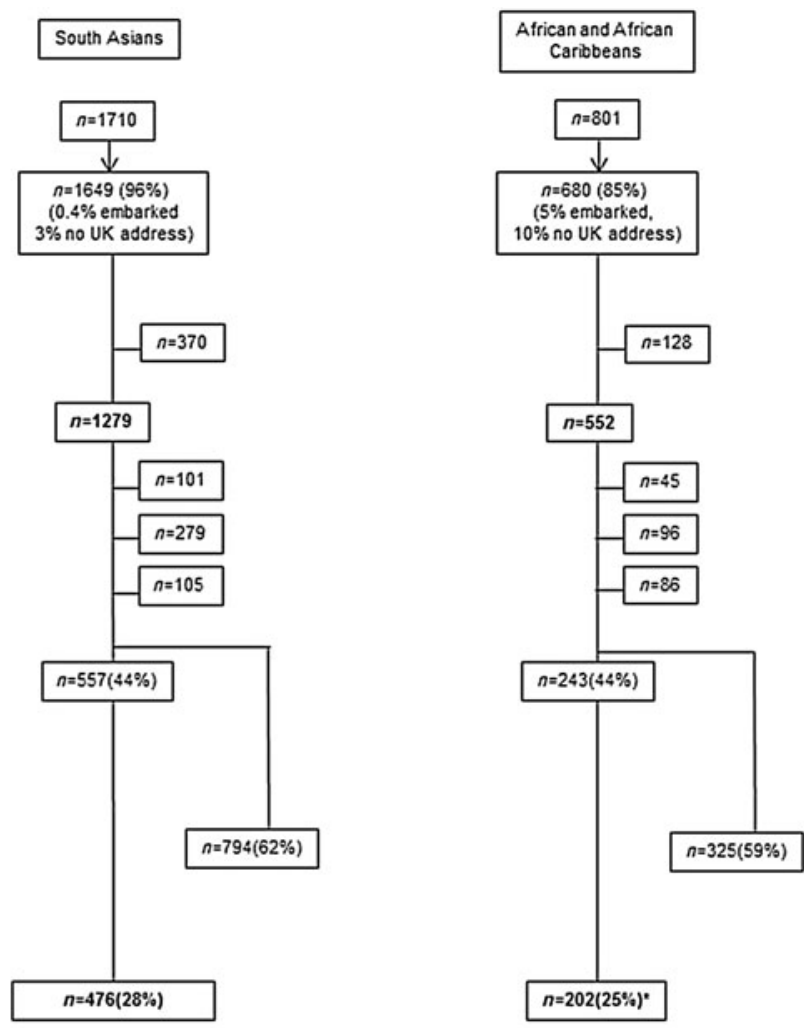

The main analyses used logistic regression to analyse ethnic group differences in depressive symptoms (reference category: White Europeans). We then wished to explore the impact of key factors, including socioeconomic position (SEP), chronic disease (either at baseline or follow-up) and functional limitation, in accounting for any ethnic differences observed in depressive symptoms. For example, we hypothesized that lower SEP in Black Caribbeans may determine excess levels of depressive symptoms; we therefore anticipated that adjustment for SEP would attenuate the Black Caribbean $v$. European odds ratio (OR). We first present each adjustment for individual groups of explanatory variables in turn, and then present a final multivariate model including all potential explanatory variables. Thus all models controlled for age and sex: model 1: age and sex only; model 2: SEP (manual labour, homeownership); model 3: stressful life events; model 4: baseline (4a) and follow-up (4b) health behaviours (smoking, physical activity); model 5: baseline (5a) and follow-up (5b) clinical factors/co-morbidities [waist circumference, diabetes, coronary heart disease (CHD), hypertension, stroke (follow-up only), functional limitation (follow-up only)]; model 6: cognitive function; model 7: depression/anxiety medication; model 8: adjustment for 
Table 1. Variables measured at baseline and follow-up

\begin{tabular}{|c|c|c|}
\hline Variables & Scale & Measurement/categorization \\
\hline \multicolumn{3}{|c|}{ Clinic visit - baseline (conducted by trained research staff) } \\
\hline \multicolumn{2}{|c|}{$\begin{array}{l}\text { Waist } \\
\text { circumference }\end{array}$} & $\begin{array}{l}\text { Measurement taken halfway between costal margin } \\
\text { and iliac crest }\end{array}$ \\
\hline \multicolumn{2}{|l|}{ Hip circumference } & Measurement taken over greater trochanter \\
\hline \multicolumn{2}{|l|}{ Diabetes } & $\begin{array}{l}\text { Identified from medical record or participant recall } \\
\text { of diagnosis }\end{array}$ \\
\hline \multicolumn{2}{|l|}{$\begin{array}{l}\text { Coronary heart } \\
\text { disease }\end{array}$} & $\begin{array}{l}\text { Identified by data extracted from primary-care } \\
\text { records (Tillin } \text { et al. 2012) }\end{array}$ \\
\hline \multicolumn{2}{|l|}{ Stroke } & $\begin{array}{l}\text { Recorded according to primary-care data or } \\
\text { participant report }\end{array}$ \\
\hline \multicolumn{2}{|l|}{ Hypertension } & $\begin{array}{l}\text { Recorded according to primary-care data or } \\
\text { participant report }\end{array}$ \\
\hline \multicolumn{3}{|c|}{ Questionnaire - baseline (self-reported) } \\
\hline \multirow{2}{*}{$\begin{array}{l}\text { Socioeconomic } \\
\text { position }\end{array}$} & Manual labour & Dichotomized into manual v. non-manual \\
\hline & Home tenure & Dichotomized into own home v. do not own home \\
\hline Physical activity & $\begin{array}{l}\text { Total weekly energy expended (MJ) in sport, } \\
\text { walking and cycling, using questions and energy } \\
\text { expenditure estimates (Durnin \& Passmore, 1967) }\end{array}$ & $\begin{array}{l}\text { Logarithmically transformed to accommodate } \\
\text { negatively skewed data }\end{array}$ \\
\hline Smoking & Smoking history & Dichotomized into current v. ex/never smoker \\
\hline \multicolumn{3}{|c|}{ Clinic visit - follow-up (conducted by trained research staff) } \\
\hline $\begin{array}{l}\text { Depressive } \\
\text { symptoms }\end{array}$ & $\begin{array}{l}\text { 10-item version of the Geriatric Depression Scale } \\
\text { (GDS; D'Ath et al. 1994), well-validated in } \\
\text { multi-ethnic samples (Abas et al. 1998) }\end{array}$ & $\begin{array}{l}\text { Case-level depressive symptoms were defined as a } \\
\text { score of } \geqslant 4 / 10 \text {. The internal consistency for this } \\
\text { scale was satisfactory (Cronbach's } \alpha \text { : White } \\
\text { European }=0.66 \text {; South Asian }=0.72 \text {; African } \\
\text { Caribbean }=0.69 \text { ) }\end{array}$ \\
\hline \multicolumn{2}{|l|}{$\begin{array}{l}\text { Waist } \\
\text { circumference }\end{array}$} & $\begin{array}{l}\text { Measurement taken halfway between costal margin } \\
\text { and iliac crest }\end{array}$ \\
\hline \multicolumn{2}{|l|}{ Hip circumference } & Measurement taken over greater trochanter \\
\hline \multicolumn{2}{|l|}{ Diabetes } & $\begin{array}{l}\text { Identified from medical record, participant recall of } \\
\text { diagnosis, or follow-up oral glucose tolerance test }\end{array}$ \\
\hline \multicolumn{2}{|l|}{$\begin{array}{l}\text { Coronary heart } \\
\text { disease }\end{array}$} & $\begin{array}{l}\text { Identified by data extracted from primary-care } \\
\text { records (Tillin et al. 2012) }\end{array}$ \\
\hline \multicolumn{2}{|l|}{ Stroke } & $\begin{array}{l}\text { Recorded according to primary-care data or } \\
\text { participant report }\end{array}$ \\
\hline \multicolumn{2}{|l|}{ Hypertension } & $\begin{array}{l}\text { Recorded according to primary-care data or } \\
\text { participant report }\end{array}$ \\
\hline $\begin{array}{l}\text { Cognitive } \\
\text { function }\end{array}$ & $\begin{array}{l}\text { Delayed word recall scores using the CERAD } \\
\text { 10-word recall test (Morris et al. 1989) }\end{array}$ & $\begin{array}{l}\text { Participants presented with } 10 \text { words on } 3 \text { occasions } \\
\text { and were asked to recall them again after a delay of } \\
\text { a few minutes. The number of correct words } \\
\text { recalled after the delay was recorded }\end{array}$ \\
\hline \multicolumn{3}{|c|}{ Questionnaire - follow-up (self-reported) } \\
\hline $\begin{array}{l}\text { Stressful life } \\
\text { events }\end{array}$ & $\begin{array}{l}\text { Life events scale assessed stressful life events over } \\
\text { the preceding } 2 \text { years }\end{array}$ & $\begin{array}{l}\text { List of } 9 \text { potentially stressful events; a dichotomous } \\
\text { variable identified the presence or not of any } \\
\text { stressful event over this period }\end{array}$ \\
\hline \multicolumn{2}{|l|}{ Social contact } & $\begin{array}{l}\text { Measured by asking participants how many hours } \\
\text { per week they spend with friends or family }\end{array}$ \\
\hline Health state & EQ-5D (www.euroqol.org) (EQ-5D) & $\begin{array}{l}\text { EQ-5D values transformed in a utility score using } \\
\text { weights from the Measurement and Valuation of } \\
\text { Health time trade-off (TTO) set of weights } \\
\text { (Measurement and Valuation of Health Group, } \\
\text { 1995; Dolan, 1997) }\end{array}$ \\
\hline Physical activity & $\begin{array}{l}\text { Total weekly energy expended (MJ) in sport, } \\
\text { walking and cycling, using questions and energy } \\
\text { expenditure estimates (Durnin \& Passmore, 1967) }\end{array}$ & $\begin{array}{l}\text { Logarithmically transformed to accommodate } \\
\text { negatively skewed data }\end{array}$ \\
\hline
\end{tabular}


Table 1 (cont.)

\begin{tabular}{|c|c|c|}
\hline Variables & Scale & Measurement/categorization \\
\hline Smoking & Smoking history & Dichotomized into current $v$. ex/never smoker \\
\hline $\begin{array}{l}\text { Alcohol } \\
\text { consumption }\end{array}$ & Regularity of consumption & $\begin{array}{l}\text { Categorized into } 5 \text { groups (never/special occasions } \\
\text { only, once/twice a month, once/twice a week, four/five } \\
\text { times a week, daily) }\end{array}$ \\
\hline $\begin{array}{r}\text { Functional } \\
\text { limitation }\end{array}$ & & $\begin{array}{l}\text { Impairment recorded if participants reported } \\
\text { limitation with } \geqslant 1 \text { of following: (1) walking } \\
\text { unaided without stopping and discomfort; ( } 2 \text { ) } \\
\text { walking up and down a flight of } 12 \text { stairs without } \\
\text { resting; (3) bending down to pick up a shoe from } \\
\text { the floor }\end{array}$ \\
\hline
\end{tabular}

all covariates. The formula used to calculate the proportion of the association explained by adjustment was

$\left.\left(\mathrm{OR}_{\text {basic model }}-\mathrm{OR}_{\text {adjusted }}\right) / \mathrm{OR}_{\text {basic model }}-1\right) \times 100$.

Sex by ethnicity interactions tested established sex differences in depressive symptoms (albeit less marked among older groups (Bebbington et al. 1998), but were found to be non-significant and not pursued further.

Because of missing data on alcohol consumption and social contact, these variables were excluded from the main analyses, and subgroup analyses were performed to check any impact on the main findings for ethnic group differences in depressive symptoms. Statistical analyses were performed using SPSS v. 20 (SPSS Inc., USA).

\section{GDS validation}

To explore the equivalence of the GDS across the ethnic groups, differential item functioning (DIF) analyses were used to determine whether item bias was detected between ethnic groups (White European group as the reference category). For the identification of DIF, non-parametric tests within the DIFAS 4.0 program were used (Penfeld, 2007). The process used to measure DIF was the Mantel $\chi^{2}$ values (Mantel) and the Standardized Liu-Agresti Cumulative Common Log-odds ratio values (LOR Z). The EQ-5D was developed by the EuroQol group as a brief, self-completed measure of follow-up health state, rating five dimensions (mobility, self-care, usual activities, pain/discomfort, anxiety/depression) in three levels (no problems, some problems, extreme problems). A utility score was generated from the EQ-5D values using the Measurement and Valuation of Health time trade-off (TTO) set of weights (Measurement and Valuation of Health Group, 1995; Dolan, 1997). Taking advantage of its completion in this cohort, and in order to explore the construct validity of the GDS, bivariate correlations examined the relationship between the GDS and EQ-5D utility score and compared the strengths of this association between the three ethnic groups. Correlations were performed using SPSS v. 20.

\section{Results}

Participants who attended follow-up clinics (therefore providing GDS data) differed from other survivors (follow-up responders without GDS data and nonresponders) on baseline characteristics. People who did not attend clinics were younger $(p<0.001)$, more likely to be female $(p=0.006)$, have lower SEP $(p<0.001)$, and have poor self-rated health $(p=0.002)$. These differences applied equally across ethnic groups and clinic attendance rates were very similar across ethnic groups (44\% European, 43\% South Asian, 46\% Black Caribbean).

\section{Comparison of characteristics (Table 2)}

South Asian people were younger than White Europeans and Black Caribbean participants had a higher proportion of women than men. Both minority ethnic groups reported more manual occupation employment and less alcohol consumption compared with White Europeans. Although baseline and followup waist circumference was lower in South Asian than White European participants, prevalence of baseline and follow-up diabetes, follow-up CHD, and followup functional limitation were significantly higher. The Black Caribbean group showed increased prevalence of baseline and follow-up diabetes and follow-up functional limitation.

Overall, $13.0 \%$ of participants reported depressive symptoms, $9.7 \%$ of White European, $15.5 \%$ of South Asian (14.7\% Indian, 21.1\% Pakistani, 16.7\% East African Asian), and $17.7 \%$ of Black Caribbean participants), a statistically significantly higher prevalence among both minority ethnic groups compared with 
Table 2. Characteristics of participants by ethnic group

\begin{tabular}{|c|c|c|c|}
\hline & White European $(n=632)$ & South Asian $(n=476)$ & Black Caribbean $(n=181)$ \\
\hline Age (years) & $69.9 \pm 6.3$ & $68.7 \pm 5.9^{*}$ & $70.7 \pm 5.8^{*}$ \\
\hline Sex (\% male) & 78.3 & 86.6 & $48.6^{*}$ \\
\hline \multicolumn{4}{|l|}{ Baseline } \\
\hline Manual labour: Manual & 51.9 & $68.7^{*}$ & $66.9^{*}$ \\
\hline Home ownership: Own home & 87.0 & $95.0^{*}$ & $70.2^{*}$ \\
\hline \multicolumn{4}{|l|}{ Smoking (\%) } \\
\hline Ex/never & 79.1 & 89.9 & 84.0 \\
\hline Current & 20.9 & $10.1^{*}$ & 16.0 \\
\hline Physical activity (hours/week) & $10.8(7.0-16.0)$ & $9.3(5.5-13.0)$ & $11.0(7.0-15.1)$ \\
\hline Waist:hip ratio & $0.90 \pm 0.09$ & $0.95 \pm 0.08^{*}$ & $0.89 \pm 0.08^{*}$ \\
\hline Waist circumference $(\mathrm{cm})$ & $88.0 \pm 11.8$ & $90.1 \pm 9.4^{*}$ & $87.7 \pm 10.3^{*}$ \\
\hline Diabetes $(\%)$ & 2.5 & $13.4^{*}$ & $10.5^{*}$ \\
\hline Coronary heart disease $(\%)$ & 5.9 & 5.9 & 8.9 \\
\hline Stroke $(\%)$ & 0.2 & 0.2 & 1.0 \\
\hline Hypertension (\%) & 4.1 & $9.9^{*}$ & $22.7^{*}$ \\
\hline \multicolumn{4}{|l|}{ Follow-up } \\
\hline \multicolumn{4}{|l|}{ Marital status (\%) } \\
\hline Married/cohabiting & 67.7 & $85.9^{*}$ & $54.2^{*}$ \\
\hline Single & 10.2 & 1.9 & 11.7 \\
\hline Divorced/separated & 11.7 & 2.1 & 20.1 \\
\hline Widowed & 10.4 & 10.2 & 14.0 \\
\hline Depressive symptoms (\%) & 9.7 & $15.5^{*}$ & $17.7^{*}$ \\
\hline $\begin{array}{l}\text { Antidepressant/anxiolytic medication (\% } \\
\text { taking) }\end{array}$ & 4.7 & 3.2 & 5.0 \\
\hline Stressful life events (\% reporting any) & 55.4 & $49.2^{*}$ & 59.7 \\
\hline Social contact (hours/week) & $9.0(4.0-20.0)$ & $8.6(3.9-20.0)$ & $6.5(3.0-15.8)^{*}$ \\
\hline \multicolumn{4}{|l|}{ Smoking (\%) } \\
\hline Ex/never & 92.7 & 95.8 & 95.6 \\
\hline Current & 7.3 & $4.2^{*}$ & 4.4 \\
\hline Physical activity (hours/week) & $3.8(1.8-5.8)$ & $3.8(1.8-4.7)^{*}$ & $3.8(1.8-4.7)^{*}$ \\
\hline \multicolumn{4}{|l|}{ Alcohol intake $(\%)$} \\
\hline Daily & 21.8 & 20.1 & 6.3 \\
\hline Four/five times a week & 21.6 & 16.1 & 8.9 \\
\hline Once/twice a week & 24.7 & 27.5 & 22.2 \\
\hline Once/twice a month & 11.7 & 8.7 & 13.9 \\
\hline Never/special occasions & 20.1 & $27.5^{*}$ & $48.7^{*}$ \\
\hline Waist:hip ratio & $0.97 \pm 0.07$ & $1.00 \pm 0.07^{*}$ & $0.96 \pm 0.08^{*}$ \\
\hline Waist circumference $(\mathrm{cm})$ & $100.1 \pm 13.3$ & $97.8 \pm 10.2^{*}$ & $97.7 \pm 12.1$ \\
\hline Diabetes $(\%)$ & 19.3 & $42.1^{*}$ & $39.2^{*}$ \\
\hline Coronary heart disease (\%) & 20.4 & $34.5^{*}$ & 13.2 \\
\hline Stroke $(\%)$ & 2.7 & 2.1 & 5.0 \\
\hline Hypertension (\%) & 55.2 & $75.2^{*}$ & $77.9^{*}$ \\
\hline Functional limitation (\%) & 14.7 & $32.8^{*}$ & $29.8^{*}$ \\
\hline Cognitive function (no. of recalled words) & $6.1 \pm 2.0$ & $5.8 \pm 2.0^{*}$ & $5.1 \pm 2.1^{*}$ \\
\hline
\end{tabular}

Data presented are unadjusted means (S.D.) and \%, with exception of social contact and physical activity, presented as medians (interquartile range), due to skewed data.

${ }^{*} p<0.05$ for age- and sex-adjusted group differences with White European as the reference category.

their European counterparts $(p=0.004$ and $p=0.001$, respectively). The prevalence of depressive symptoms was higher in women than men, but this was not statistically significant (White European: $10.2 \%$ v. 9.5\%, $p=0.93$; South Asian: $20.3 \%$ v. $14.8 \%, p=0.34$; Black Caribbean: $22.6 \%$ v. $12.5 \%, p=0.11$, respectively).
Ethnic group differences in depressive symptoms between South Asian and White European participants (Table 3 )

South Asian participants had significantly elevated odds [OR 1.79, 95\% confidence interval (CI) 
1.24-2.58] of having depressive symptoms compared with White Europeans (model 1). Socioeconomic, stressful life event (follow-up), and behavioural characteristics (models 2-4) had little impact on odds ratios. While baseline clinical factors/co-morbidities did not affect the odds ratios (model 5a), the follow-up measures of these variables accounted for most of the elevated odds of depressive symptoms, 65\% (model $5 b)$, reducing the ethnic difference to non-significance. This was explored further and functional limitation alone accounted for an additional $67 \%$ of the excess odds, after adjustment for other baseline and follow-up co-morbidities. Cognitive function and antidepressant/ anxiolytic medication use (models 6-7) did not affect the differences observed. In the fully adjusted model 8, the South Asian odds remained significantly elevated compared with White Europeans.

\section{Ethnic group differences in depressive symptoms between Black Caribbean and White European participants (Table 3)}

Black Caribbean participants were significantly more likely to report depressive symptoms compared with White Europeans (OR 1.80, 95\% CI 1.11-2.92). Socioeconomic disadvantage (model 2) explained a substantial proportion of the elevated odds observed $(43 \%)$, while psychosocial, behavioural, and clinical factors/co-morbidity factors had only marginal effects on the excess depressive symptoms in this group (models 3-5). Cognitive function (model 6) accounted for $23 \%$ of the elevated odds of depressive symptoms among Black Caribbean participants, while antidepressant/anxiolytic medication use did not affect this differential (model 7). Full adjustment (model 8) did not attenuate the elevated odds ratio, thus Black Caribbeans were nearly twice as likely to report depressive symptoms even when other factors were taken into account.

Alcohol intake and social contact were included in separate versions of model 8 and did not qualitatively affect the findings of the main analyses.

\section{GDS validation}

No GDS items elicited Mantel scores $>6.63$ in either the South Asian or Black Caribbean responses, compared with those of White Europeans [the maximum value above which group differences in response to the studied items are indicated (Penfeld, 2007)]. Similarly, none of the LOR $Z$ values were greater than 2.0 or less than -2.0 (reflecting DIF effect size). Therefore, no DIF was identified for the GDS. The correlations for GDS and EQ-5D utility scores were comparable across ethnic groups $[r=-0.38$ for White European $(p<0.001)$,
Table 3. Odds of having depressive symptoms for South Asian and Black Caribbean participants (compared with White European participants)

\begin{tabular}{|c|c|c|}
\hline & $\begin{array}{l}\text { South Asian } \\
\text { OR ( } 95 \% \text { CI) }\end{array}$ & $\begin{array}{l}\text { Black } \\
\text { Caribbean } \\
\text { OR }(95 \% \mathrm{CI})\end{array}$ \\
\hline $\begin{array}{l}\text { Model 1: Adjusted for age } \\
\text { and sex }\end{array}$ & $1.79(1.24-2.58)$ & $1.80(1.11-2.92)$ \\
\hline $\begin{array}{l}\text { Model 2: Adjusted for } \\
\text { age, sex, and } \\
\text { socioeconomic position }\end{array}$ & $1.80(1.23-2.63)$ & $1.46(0.89-2.39)$ \\
\hline $\begin{array}{l}\text { Model 3: Adjusted for } \\
\text { age, sex, and stressful } \\
\text { life events }\end{array}$ & $1.86(1.29-2.69)$ & $1.76(1.08-2.87)$ \\
\hline $\begin{array}{l}\text { Model 4a: Adjusted for } \\
\text { age, sex, and baseline } \\
\text { health behaviours }\end{array}$ & $1.86(1.26-2.74)$ & $1.93(1.18-3.13)$ \\
\hline $\begin{array}{l}\text { Model } 4 \mathrm{~b} \text { : Adjusted for } \\
\text { age, sex, and follow-up } \\
\text { health behaviours }\end{array}$ & $1.71(1.17-2.49)$ & $1.88(1.15-3.10)$ \\
\hline $\begin{array}{l}\text { Model 5a: Adjusted for } \\
\text { age, sex, and baseline } \\
\text { clinical risk factors/ } \\
\text { co-morbidities }\end{array}$ & $1.79(1.22-2.60)$ & $1.91(1.15-3.16)$ \\
\hline $\begin{array}{l}\text { Model 5b: Adjusted for } \\
\text { age, sex, and follow-up } \\
\text { clinical risk factors/ } \\
\text { co-morbidities }\end{array}$ & $1.28(0.84-1.94)$ & $1.81(1.07-3.04)$ \\
\hline $\begin{array}{l}\text { Model 6: Adjusted for } \\
\text { age, sex, and cognitive } \\
\text { function }\end{array}$ & $1.71(1.18-2.47)$ & $1.62(0.99-2.64)$ \\
\hline $\begin{array}{l}\text { Model 7: Adjusted for } \\
\text { age, sex, and depression/ } \\
\text { anxiety medication }\end{array}$ & $1.85(1.28-2.68)$ & $1.83(1.12-2.98)$ \\
\hline $\begin{array}{l}\text { Model 8: Adjustment for } \\
\text { all covariates }\end{array}$ & $1.63(1.02-2.60)$ & $1.98(1.12-3.49)$ \\
\hline
\end{tabular}

OR, Odds ratio; $\mathrm{CI}$, confidence interval.

Reference category: White European. Model 2 included adjustment for manual occupation and home ownership; model 4a included adjustment for baseline smoking and physical activity; model $4 \mathrm{~b}$ included adjustment for followup smoking and physical activity; model 5a included adjustment for baseline waist circumference, diabetes, coronary heart disease, and hypertension; model $5 \mathrm{~b}$ included adjustment for follow-up waist circumference, diabetes, coronary heart disease, stroke, hypertension, and functional limitation.

$r=-0.35$ for South Asian $(p<0.001), r=-0.30$ for Black Caribbean participants $(p<0.001)$ ].

Interestingly, one item referring to whether people thought that most other people were better off than them was more heavily endorsed by the South Asian and Black Caribbean participants, compared with the White Europeans (19\% of South Asian, 20\% of Black 
Caribbean and 5\% of White European participants responded positively to this question). Removal of this item did not significantly influence the results.

\section{Discussion}

Older first-generation migrants of South Asian and Black Caribbean origin to the UK were nearly twice as likely to report depressive symptoms as their European origin counterparts. Different factors appeared to account for this excess. In South Asians, these factors included a greater degree of later-life chronic disease, while in Black Caribbeans the key contributor appeared to be socioeconomic disadvantage.

\section{Strengths and limitations}

Depression is highly prevalent in older populations (Osborn et al. 2003). This study provides the largest comparison of depressive symptoms among the UK's three most populous ethnic groups within this age range, recruited from the general population. Other major strengths are the range of possible longitudinal mid- and late-life factors assessed, and the use of a depression measure with evidence of cross-cultural validity designed specifically for use in older people. However, there are some limitations. The primary outcome only ascertained symptomatology on a relatively brief screening instrument that was not a diagnostic instrument; nonetheless, this instrument strongly predicts subsequent depressive symptoms (Vinkers et al. 2004). The attrition during follow-up and missing data mean that our sample may be subject to selection bias. We compared baseline characteristics of those with and without GDS data, and we showed that healthier individuals and those with higher SEP were more likely to re-attend. This differential response applied equally to all ethnic groups; thus the observed ethnic group variations in depressive symptoms are unlikely to have been influenced by this bias. The study's crosssectional ascertainment of depressive symptoms at follow-up preclude conclusions around direction of causality [because symptomatology in mid-life (baseline) and the intervening period were not recorded] and does not capture the episodic nature of depression (although incorporation of data on antidepressant use may help to some limited extent). While adjustment for stressful life events did not markedly alter the ethnic difference in reported depressive symptoms for either South Asians or Black Caribbeans, we acknowledge that these events may be differently remembered, or have different impacts by ethnicity. Factors included in our models may act as causal determinants, confounders or consequences of depressive symptoms and it is possible, for example, that adjustment for physical disease represented an over-adjustment if this was a consequence of depressive symptoms. Furthermore, we could not measure all factors that may account for ethnic differences in depressive symptoms.

\section{Comparison with previous studies}

An East London study found substantially elevated depression prevalence among Bengali compared with Somali and White British older participants, citing, but not testing, socioeconomic variables and social support as potential explanations (Silveira \& Ebrahim, 1998). By contrast, a comparison of Gujarati and White people aged $>65$ years from Leicester showed no ethnic differences in depression (Lindesay et al. 1997). Data from the USA indicate an excess depression prevalence among Black American compared with White participants (Skarupski et al. 2005), which was only partially attenuated after adjustment for socioeconomic characteristics, although another study found no significant difference in the same scores using the same instrument between African American and White older adults (Blazer et al. 1998). However, generalizing between ethnic groups in different countries is limited because of substantial differences in SEP, social integration and migration history.

\section{Depressive symptoms in South Asians}

The excess depressive symptomatology among South Asian people observed here was largely attenuated by functional limitation adjustment (Table 3 model $5 b)$, suggesting that the elevated disability risk among South Asian people (Williams et al. 2012) may contribute to higher depressive symptoms. Differences in body composition and chronic disease are well established between UK White and South Asian groups (Bhopal et al. 1999) but did not appear to account for the difference in depressive symptoms, beyond the impact of disability. Although subgroup analyses were not possible, unadjusted prevalences of depressive symptoms were higher among all South Asian subgroups than White Europeans, consistent with some earlier research (Williams et al. 2010), but not others (Nazroo, 1997). The predominant subgroup in this sample was Punjabi Sikh (53\%), who tend to occupy a higher SEP than other subgroups (Williams et al. 2010), and our results may therefore underestimate the prevalence of depressive symptoms in South Asian communities as a whole.

\section{Depressive symptoms in Black Caribbeans}

Adjustment for socioeconomic measures and cognitive function attenuated the excess depressive symptoms in 
Black Caribbean participants. UK Black Caribbean people have often experienced socioeconomic disadvantage (Smith et al. 2000), which is a well-recognized risk factor for depression (Katon et al. 2004). Other socioeconomic characteristics, such as wealth, were not taken into account and therefore may have contributed further to the excess prevalence of depressive symptoms in this group. However, there is a surprising dearth of comparable data in this group and further work is needed to confirm our findings.

\section{Validity of depression questionnaire}

It is important to bear in mind potential differences in interpretation when comparing depression measurements between ethnic groups (Nazroo, 1997), and qualitative research has, for example, found significant variations in mental distress language and presentation between White and Pakistani people, explaining different patterns of help-seeking and health outcomes (Mallinson \& Popay, 2007). However, our analyses of GDS performance and cultural equivalence did not suggest consistent differences between the three ethnic groups in the probability of giving a certain GDS response, suggesting similar interpretation of questions across groups, and supporting previous validation of this instrument (Abas et al. 1998). In addition, there was no meaningful difference in the correlation between GDS and EQ-5D scores, although it should be borne in mind that these analyses, although supportive, represented an opportunistic use of available data and the cohort study was not formally designed to assess the validity of the GDS. Our assessment of the GDS validity did not test all components of validity that are necessary to comprehensively evaluate the cultural equivalence of this instrument (Flaherty et al. 1988).

\section{Unmeasured explanations}

High levels of endorsement of the GDS item associated with feelings of relative disadvantage by the South Asian and Black Caribbean participants were found. This may reflect experiences of discrimination (Smith et al. 2000) but additional focused research would be needed to clarify this. Indeed, it is important to bear in mind that there are other psychosocial and cultural explanations that were insufficiently measured. Racial discrimination is a risk factor for depression (Karlsen et al. 2005), with experience of interpersonal and institutionalized racism shown to be particularly associated with worse mental health (Karlsen et al. 2005). Research exploring depression in UK South Asian populations has implicated the role of culture conflict as a potential cause (Hussain \& Cochrane, 2002; Bhugra, 2003; Gask et al. 2011), possibly particularly in first-generation migrants and South Asian women for whom acculturation levels can be lower (Ghuman, 2000). Family conflict as younger generations assimilate has also been associated with depression among older South Asian people (Sonuga-Barke \& Mistry, 2000). Since all minority ethnic participants were first-generation migrants, the differences in depressive symptoms may reflect issues associated with migration (Bhugra, 2003), rather than ethnicity. Bhugra's migration and depression review highlights the importance of social support and isolation resulting from migration (Bhugra, 2003), and isolation was seen as contributing to depression onset and maintenance among depressed Pakistani women in North-West England (Gask et al. 2011).

This study's findings present important implications for depression prevention and treatment. Economic evaluation of interventions to reduce physical disease throughout mid- and late-life should acknowledge the possible beneficial effects these may also have on subsequent mental health and its sequelae. Social policy interventions should also recognize the benefits to mental health inequalities. Limited evidence suggests that receipt of medication for depression is less common in ethnic minority groups, perhaps in part reflecting the difficulty in diagnosis or cultural differences in acceptability. Our findings require replication and their generalizability needs to be clarified - both to other ethnic groups, and to subsequent generations whose health status, behaviours, socioeconomic status and acculturation may differ. It is important that general and mental health practitioners are aware of these elevated depressive symptom prevalences among certain ethnic groups, and are able to recognize other factors, such as co-morbidities, that might identify individuals at 'high risk'. Equitable access to mental health services with effective and culturally appropriate treatment must be available for vulnerable groups.

\section{Acknowledgements}

We acknowledge the contribution of the SABRE research team and participants, as well as from Dr Sophie Eastwood for her comments. The SABRE study was supported by a joint programme grant from the Wellcome Trust and British Heart Foundation (BHF). The pilot follow-up study was supported by the BHF. The Southall Study was supported by the UK Medical Research Council, the British Diabetic Association (now Diabetes UK), the Wellcome Trust and the BHF. The Brent Study was supported by the UK Medical Research Council. E.D.W. was funded by a Diabetes UK fellowship (09/0003833). R.S. is part-funded by the National Institute for Health Research (NIHR) Biomedical Research Centre at South London and 
Maudsley NHS Foundation Trust and King's College London.

\section{References}

Abas MA, Phillips C, Carter J, Walter J, Banerjee S, Levy R (1998). Culturally sensitive validation of screening questionnaires for depression in older African-Caribbean people living in south London. British Journal of Psychiatry 173, 249-254.

Bebbington PE, Dunn G, Jenkins R, Lewis G, Brugha T, Farrell M. Meltzer H (1998). The influence of age and sex on the prevalence of depressive conditions: report from the National Survey of Psychiatric Morbidity. Psychological Medicine 28, 9-19.

Bhopal R, Unwin N, White M, Yallop J, Walker L, Alberti KGMM, Harland J, Patel S, Ahmad N, Turner C, Watson B, Kaur D, Kulkarni A, Laker M, Tavridou A (1999). Heterogeneity of coronary heart disease risk factors in Indian, Pakistani, Bangladeshi, and European origin populations: cross sectional study. British Medical Journal 319, 215-220.

Bhugra D (2003). Migration and depression. Acta Psychiatrica Scandinavica 108, 67-72.

Blazer D, Burchett B, Service C, George LK (1991). The association of age and depression among the elderly: an epidemiologic exploration. Journal of Gerontology 46, M210-M215.

Blazer DG, Kessler RC, McGonagle KA, Swartz MS (1994). The prevalence and distribution of major depression in a national community sample: the National Comorbidity Survey. American Journal of Psychiatry 151, 979-986.

Blazer DG, Landerman LR, Hays JC, Simonsick EM, Saunders WB (1998). Symptoms of depression among community-dwelling elderly African-American and white older adults. Psychological Medicine 28, 1311-1320.

Craig R, Doyle M, Jotangia D (2006). Eating habits. In Health Survey for England 2004 Volume 1: The Health of Minority Ethnic Groups (ed. K. Sproston and J. Mindell), pp. 263-300. The Information Centre: London.

D'Ath P, Katona P, Mullan E, Evans S, Katona C (1994). Screening, detection and management of depression in elderly primary care attenders. I: the acceptability and performance of the 15 Item Geriatric Depression Scale (GDS15) and the development of short versions. Family Practice 11, 260-266.

Dolan P (1997). Modeling valuations for EuroQol health states. Medical Care 35, 1095-1108.

Durnin J, Passmore R (1967). Energy, Work and Leisure. Heinemann: London.

Fischbacher C, Bhopal R, Povey C, Steiner M, Chalmers J, Mueller G, Jamieson J, Knowles D (2007). Record linked retrospective cohort study of 4.6 million people exploring ethnic variations in disease: myocardial infarction in South Asians. BMC Public Health 7, 142.

Flaherty JA, Gaviria FM, Pathak D, Mitchell T, Wintrob R, Richman JA, Birz S (1988). Developing instruments for cross-cultural psychiatric research. Journal of Nervous and Mental Disorders 176, 257-263.
Gask L, Aseem S, Waquas A, Waheed W (2011). Isolation, feeling 'stuck' and loss of control: Understanding persistence of depression in British Pakistani women. Journal of Affective Disorders 128, 49-55.

Ghuman PAS (2000). Acculturation of South Asian adolescents in Australia. British Journal of Educational Psychology 70, 305-316.

Husaini BA, Moore ST (1990). Arthritis disability, depression, and life satisfaction among black elderly people. Health and Social Work 15, 253-260.

Hussain FA, Cochrane R (2002). Depression in South Asian women: Asian women's beliefs on causes and cures. Mental Health Religion Culture 5, 285-311.

Karlsen S, Nazroo JY, McKenzie K, Bhui K, Weich S (2005). Racism, psychosis and common mental disorder among ethnic minority groups in England. Psychological Medicine 35, 1795.

Katon W, Von Korff M, Ciechanowski P, Russo J, Lin E, Simon G, Ludman E, Walker E, Bush T, Young B (2004). Behavioral and clinical factors associated with depression among individuals with diabetes. Diabetes Care 27, 914-920.

Lindesay J, Jagger C, Hibbett MJ, Peet SM, Moledina F (1997). Knowledge, uptake and availability of health and social services among Asian Gujarati and white elderly persons. Ethnicity and Health 2, 59-69.

Mallinson S, Popay J (2007). Describing depression: ethnicity and the use of somatic imagery in accounts of mental distress. Sociology of Health and Illness 29, 857-871.

Measurement and Valuation of Health Group (1995). The Measurement and Valuation of Health. Final Report on the Modelling of Valuation Tariffs. Centre for Health Economics: York.

Morris JC, Heyman A, Mohs RC, Hughes JP, van Belle G, Fillenbaum G, Mellits ED, Clark C (1989). The consortium to establish a registry for Alzheimer's disease (CERAD). Part 1. Clinical and neuropsychological assessment of Alzheimer's disease. Neurology 39, 1159-65.

Nazroo JY (1997). Ethnicity and Mental Health: Findings from National Community Survey. Policy Studies Institute: London.

Nazroo JY (2003). The structuring of ethnic inequalities in health: economic position, racial discrimination, and racism. American Journal of Public Health 93, 277-284.

Osborn DPJ, Fletcher AE, Smeeth L, Stirling S, Bulpitt CJ, Breeze E, Ng ESW, Nunes M, Jones D, Tulloch A (2003). Factors associated with depression in a representative sample of 14217 people aged 75 and over in the United Kingdom: results from the MRC trial of assessment and management of older people in the community. International Journal of Geriatric Psychiatry 18, 623-630.

Penfeld R (2007). DIFAS 4.0: Differential item functioning analysis system: user's manual.

Silveira E, Ebrahim S (1995). Mental health and health status of elderly Bengalis and Somalis in London. Age and Ageing 24, 474-480.

Silveira ERT, Ebrahim S (1998). Social determinants of psychiatric morbidity and well-being in immigrant elders and whites in east London. International Journal of Geriatric Psychiatry 13, 801-812. 
Simpson SM, Krishnan LL, Kunik ME, Ruiz P (2007). Racial disparities in diagnosis and treatment of depression: a literature review. Psychiatric Quarterly 78, 3-14.

Skarupski KA, Mendes de Leon CF, Bienias JL, Barnes LL, Everson-Rose SA, Wilson RS, Evans DA (2005). Blackwhite differences in depressive symptoms among older adults over time. Journals of Gerontology Series B: Psychological Sciences and Social Sciences 60, P136-42.

Smith GD, Chaturvedi N, Harding S, Nazroo J, Williams R (2000). Ethnic inequalities in health: a review of UK epidemiological evidence. Critical Public Health 10, 375-408.

Sonuga-Barke EJS, Mistry M (2000). The effect of extended family living on the mental health of three generations within two Asian communities. British Journal of Clinical Psychology 39, 129-141.

Stewart R, Prince M, Mann A, Richards M, Brayne C (2001). Stroke, vascular risk factors and depression: cross-sectional study in a UK Caribbean-born population. British Journal of Psychiatry 178, 23-28.

Tillin T, Forouhi NG, McKeigue PM, Chaturvedi N, Group ftSS (2012). Southall And Brent REvisited: cohort profile of SABRE, a UK population-based comparison of cardiovascular disease and diabetes in people of European, Indian Asian and African Caribbean origins. International Journal of Epidemiology 41, 33-42.

Tillin T, Hughes AD, Mayet J, Whincup P, Sattar N, Forouhi N, McKeigue PM, Chaturvedi N (2013). The relationship between metabolic risk factors and incident cardiovascular disease in Europeans, South Asians and African Caribbeans. SABRE (Southall and Brent REvisited) - a prospective population based study. Journal of the American College of Cardiology 61, 1777-1786.

Vinkers DJ, Stek ML, Gussekloo J, van der Mast RC, Westendorp RGJ (2004). Does depression in old age increase only cardiovascular mortality? The Leiden 85-plus Study. International Journal of Geriatric Psychiatry 19, 852-857.

Williams DR, Gonzalez HM, Neighbors H, Nesse R, Abelson JM, Sweetman J, Jackson JS (2007). Prevalence and distribution of major depressive disorder in African Americans, Caribbean blacks, and non-Hispanic whites: results from the National Survey of American Life. Archives of General Psychiatry 64, 305-315.

Williams ED, Nazroo JY, Kooner JS, Steptoe A (2010). Subgroup differences in psychosocial factors relating to coronary heart disease in the UK South Asian population. Joornal of Psychosomatic Research 69, 379-387.

Williams ED, Stamatakis E, Chandola T, Hamer M (2011). Physical activity behaviour and coronary heart disease mortality among South Asian people in the UK: an observational longitudinal study. Heart 97, 655-659.

Williams ED, Tillin T, Whincup P, Forouhi NG, Chaturvedi N (2012). Ethnic differences in disability prevalence and their determinants studied over a 20-year period: a cohort study. PLoS ONE 7, e45602.

WHO (2008). The Global Burden of Disease: 2004 Update. WHO Press: Geneva.

Yesavage JA, Brink TL, Rose TL, Lum O, Huang V, Adey M, Leirer VO (1982). Development and validation of a geriatric depression screening scale: a preliminary report. Journal of Psychiatric Research 17, 37-49. 